\title{
Hirigune historikoen babesa klima-aldaketaren aurrean: arriskua neurtzeko metodologiak
} (Safeguarding Historic Urban Areas from Climate Change: Risk Assessment Methodologies)

\author{
Laura Quesada-Ganuza ${ }^{1 *}$, Leire Garmendia ${ }^{1}$, Irantzu Álvarez ${ }^{2}$,Estibaliz Briz ${ }^{1}$, \\ Ane Villaverde \\ ${ }^{1}$ Euskal Herriko Unibertsitatea (UPV/EHU), Bilboko Ingeniaritza Eskola, \\ Ingeniaritza Mekanikoko Saila \\ ${ }^{2}$ Euskal Herriko Unibertsitatea (UPV/EHU), Bilboko Ingeniaritza Eskola, \\ Adierazpen Grafikoa eta Ingeniaritzako Proiektuen Saila
}

LABURPENA: Artikulu honetan, hirigune historikoetarako klima-aldaketarekin erlazionatutako arriskuen ebaluaziorako metodologiei buruzko egungo literaturaren berrikuspen sistematiko eta kritikoa egiten da. Horretarako, gaur egungo literaturaren azterketa sakona egin da Web of Science eta Scopus datu-baseetan, klima-aldaketaren eta ondoriozko muturreko gertaeren eraginpean dagoen kultura-ondarearen kalteberatasun eta arrisku ebaluazio-metodologiak identifikatu eta ezaugarritzeko. Etorkizunean zuzendu beharreko metodologien ezaugarriak eta ezagutza-hutsune nagusiak identifikatu dira, hirigune historikoetan bero-boladak izateko arriskua ebaluatzeko metodologia holistikorik eza barne. Aztertu egin dira berrikuspenaren emaitzak, ondoren arriskuak ebaluatzeko etorkizuneko metodologietarako adierazleak identifikatu eta garatzeko. Metodologia horiek sistema bakar gisa landuko dituzte hirigune historikoetako elementuak, eta bero-bolada luzeek izan dezaketen inpaktu potentziala landuko dute, muturreko gertaera klimatiko horien probabilitate handiagoa kontsideratuz.

HITZ GAKOAK: hirigune historikoa, klima-aldaketa, arriskuen ebaluazioa, kalteberatasunaren ebaluazioa, adierazleak.

\begin{abstract}
This article presents a systematic and critical review of the existing literature on climatechange risk assessment methodologies for historic urban areas. For this, a systematic search of the existing literature on Web of Science and Scopus was carried out, with the aim of identifying and characterizing the existing methodologies on vulnerability and risk assessment for cultural heritage exposed to the effects of climate change and the resulting extreme events. The main characteristics of the methodologies that need to be addressed in the near future and the key knowledge gaps were identified, including the lack of holistic heat wave risk assessment methodologies for historic urban areas. The results of the review are analyzed to identify and develop key performance indicators for use in future risk assessment methodologies that address both the elements of historic urban areas as a system and the potential impact of prolonged heat waves in light of increasing probability of this extreme weather events.
\end{abstract}

KEYWORDS: historic urban areas, climate change, risk assessment, vulnerability assessment, key performance indicators.

* Harremanetan jartzeko / Corresponding author: Laura Quesada-Ganuza, Euskal Herriko Unibertsitatea (UPV/EHU), Bilboko Ingeniaritza Eskola, Ingeniaritza Mekanikoko Saila. Plaza Ingeniero Torres Quevedo, s/n (48013 Bilbo). laura.quesada@ehu.eus - https://orcid.org/0000-0001-8225-575X.

Nola aipatu / How to cite: Quesada-Ganuza, Laura; Garmendia, Leire; Álvarez, Irantzu; Briz, Estibaliz; Villaverde, Ane (2022). «Hirigune historikoen babesa klima-aldaketaren aurrean: arriskua neurtzeko metodologiak»; Ekaia, ale berezia 2022, 15-30. (https://doi.org/10.1387/ekaia.23076).

Jasotze-data: 2021, irailak 23; Onartze-data: 2021, azaroak 30

ISSN 0214-9001 - elSSN 2444-3255 / (c) 2022 UPV/EHU

(c) (i) (-) $\odot$ Lan hau Creative Commons Aitortu-EzKomertziala-LanEratorririkGabe 4.0 Nazioartekoa

(c) 
Laura Quesada-Ganuza, Leire Garmendia, Irantzu Álvarez, Estibaliz Briz, Ane Villaverde

\section{SARRERA}

Azken hamarkadetako muturreko gertaera klimatikoen kopurua gero eta handiagoa dela ikusita, komunitate zientifikoan bizitu egin da klimaaldaketaren inguruko eztabaida. Beroketa globala areagotu egin da azken lau hamarkadetan, XXI. mendea orain artekoetan beroena izateraino, Munduko Meteorologia Erakundearen (WMO, ingelesezko siglak) txostenen arabera [1]. Batez besteko tenperatura globalaren igoera horrek, batez ere jarduera antropogenikoaren ondorioz, areagotu egiten du muturreko fenomenoak izateko arriskua, hala nola eurite handiak, bero-boladak eta uholdeak [2].

Munduko biztanleriaren erdia baino gehiago hiriguneetan bizi da gaur egun [3], eta tenperatura-igoera handienak hirigune horietan eta beraien eragin-eremuetan gertatzen dira [2], biztanleriaren gehiengoa eremu horietara joaten baita. Klima Aldaketarako Gobernuarteko Panelak (IPCC, ingelesezko siglak) egindako txostenak (bosgarrena, AR5) argi eta garbi adierazten du hiriguneak eta hiri-azpiegiturak, besteak beste, eraldaketa handia behar duten sistemak direla, etorkizun erresiliente bat bermatzeko. Berotze globalaren ondorio negatiboek eta muturreko gertaera meteorologikoen ondorioek nabarmen eragiten dute bertako biztanleen osasunean, ondasunetan, ongizatean eta bizigaitasunean $[2,4]$.

Hiriek inguruko eremuen baldintza klimatiko berberak badituzte ere, hiri-diseinuek mikroklimak eta bero-uharteak sortzen dituzte. Lurzoruaren iragazkortasun baxuak, dentsitate altuko eremuek, jarduera produktiboen kontzentrazio altuagoek eta hirigintza-plangintzak hiriguneak definitzen dituzte, eta horrek, klima-aldaketaren aurrean, erantzun desberdinak eragiten ditu. Hiriguneak, beraz, sistema konplexuak dira, elkarren artean erlazionaturiko geruza ezberdinez osatuak, eta ikuspegi espezifikoak behar dituzte klima-aldaketarekiko esposizioa ebaluatzeko. Nahiz eta sarritan ez den aztertzen, kultura-ondarea berezko geruza bat da hirien barruan. Hirigune historikoen ezaugarri bereziek garrantzi handia dute, hiri-nortasunaren iturri direlako eta ekonomiaren aktibo garrantzitsuak direlako. Gune historikoek eguraldi-ereduen aldaketen aurrean dituzten ahuleziak [5] ez dira eraikinen egituretan duten eragin fisikoengatik bakarrik; kultura-paisaiarentzat oso garrantzitsuak diren beste ondorio batzuengatik ere badituzte, hala nola biztanleria-ereduen aldaketarengatik, turismoaren eraginagatik eta jarduera sozioekonomikoak eteteagatik.

Azken hamarkadan, kultura-ondarea babesteko lan egiten duten erakunde esanguratsuenen arretagune bihurtu da klima-aldaketa, hala nola ICOMOSena eta UNESCOrena [6, 7]. Era berean, Europar Batasunak tinko mantentzen du bere agendan kultura-ondarearen arriskuaren ebaluazioa eta prebentzioa, batez ere EB Work Plan for Culture 2019-2022 planaren bidez, klima-aldaketara egokitzeko gai bat barne hartuta $[8,9]$. Nazio Batuen 
Hondamendi Laguntza Koordinatzailearen Bulegoak «balioa galtzeko probabilitate» gisa definitu zuen arriskua, eta kalteberatasun-indize baten bidez definitu zuen arrisku-maila (kalterik eza: 0; galera totala: 1) [10]. Beraz, hirigune historikoek klima-aldaketaren aurrean duten arriskua ebaluatzea eztabaida politikoaren erdigunean dago, eta ikerketa-eremu garrantzitsua da hirien etorkizuneko erresilientzia nola handitu daitekeen ulertzeko. Beraz, hiriguneen azterketa egiteko, kultura-ondarearen geruza eta hirigune historikoaren ezaugarri espezifikoak hartu behar dira kontuan.

Artikulu honen helburua bikoitza da. Lehenengoa hirigune historikoetarako klima-aldaketaren arriskuak ebaluatzeko metodologien egungo egoeraren berrikuspen kritikoa egitea da. Bigarren helburua arlo honetan identifikatu den ikerketa-hutsuneari erantzutea da, arrisku-ebaluaziorako metodologietan sartu beharko liratekeen funtsezko adierazleak proposatuz, bero-boladen eraginpean dauden eremu historikoen arriskuak ebaluatzeko ikuspegi holistikoa garatzeko.

\section{KLIMA-ALDAKETAREN ARRISKUAK EBALUATZEKO METODOLOGIEN BERRIKUSPEN KRITIKOA}

Atal honetan, literaturaren azterketa sistematikoaren emaitzak aurkezten dira, eremu historikoetarako klima-aldaketaren arriskuak ebaluatzeko metodologien berrikuspen kritikoa egiteko [11] eta ezagutzan dauden hutsune esanguratsuenak zehazteko. Beraz, ikerketaren galdera honako hau litzateke [12]: arriskua edo kalteberatasuna neurtzeko zein metodologia daude erlazionatuta klima-aldaketak hirigune historikoetan dituen ondorioekin? Metodologia horien berrikuspen kritikoak horien ezaugarri nagusiak ebaluatuko ditu [13]; batez ere, aztertzen diren mehatxuak eta kontuan hartzen diren arrisku-elementuak (arriskua, esposizioa, kalteberatasuna), ebaluatzen duten hiri-sistemaren alderdia barne, gure helburuetarako hirisistema hirigune historikoa dela kontuan hartuta.

Analisiaren arrisku-elementuak IPCCk eskainitako ikuspegian oinarritu dira, hori baita gehien erabiltzen den esparrua [2]. Arriskua honela definitzen da: «Gertaera arriskutsuak gertatzeko probabilitatea inpaktuekin biderkatuta, gertakari horiek gertatzen badira». Gainera, inpaktu terminoa honela definitzen da: «Muturreko fenomeno meteorologikoek eta klima-aldaketak naturan eta giza sistemetan dituzten eraginak. Inpaktuak, oro har, denbora-tarte jakin batean gertatzen diren klima-aldaketek edo fenomeno klimatiko arriskutsuek bizitzetan, biziraupen-bitartekoetan, osasunean, ekosistemetan, ekonomian, gizartean, kulturan, zerbitzuetan eta azpiegituretan dituzten ondorioei buruzkoak dira, bai eta aldaketa horien eraginpean dauden gizarteen edo sistemen kalteberatasunari buruzkoak ere» [2]. Beraz, definizio horietatik ondoriozta dezakegu arriskua mehatxuaren, kalteberata- 
Laura Quesada-Ganuza, Leire Garmendia, Irantzu Álvarez, Estibaliz Briz, Ane Villaverde

sunaren (aktibo batek duen sentikortasuna mehatxuarekiko eta horrek bere aurkako efektuei aurre egiteko duen gaitasun-ezaren konbinazioa) eta esposizioaren (aktiboaren kokapenarekin erlazionatuta) arteko elkarrekintzaren emaitza dela. Beraz, ezinbestekoa da kontuan hartzea aktibo bat mehatxu baten eraginpean egon daitekeela (esposizioa), kaltebera izan barik; aldiz, aktiboa, kaltebera izateko, mehatxuaren eraginpean egon behar da.

Hurbilketa horri jarraituz, galdera hauei erantzun beharko diegu klima-aldaketaren arriskua behar bezala ebaluatzeko: zer da mehatxua? Zer da esposizioa? Nola definituko dugu kalteberatasuna? Galdera horien erantzuna IPCCren esparruan aurki daiteke.

Esposizioari eta kalteberatasunari dagokienez, IPCCk honela definitzen du esposizioa terminoen glosarioan: «Pertsonak, bizitegi-guneak, espezie edo ekosistemak, ingurumen-funtzio, zerbitzu eta baliabideak, azpiegiturak, edo aktibo ekonomiko, sozial edo kulturalak egotea bortizki erasoak izan daitezkeen lekuetan». Esposizioa, beraz, mehatxuaren eraginpeko eremuetan dagoen elementua izan daiteke. Kalteberatasuna da arriskuaren karakterizazioaren gakoa, eta bere ebaluazioak, diziplinaren arabera, beste modu batean definitzen diren ezaugarriak eta prozesuak hartzen ditu barnean [8,9]. IPCCk bere bosgarren txostenean [2] onartu zuen definizioari jarraituko diogu kalteberatasuna zehazteko: «Muturreko gertakarien (hau da, klima-aldaketaren gertaeren) eraginpean dagoen elementu batek eragin negatiboa izateko duen joera». Definizio horrek mehatxu baten aurrean aktibo baten sentiberatasunaren eta bere efektu kontrajarriei aurre egiteko gaitasunik ezaren konbinazio bezala azaltzen du kalteberatasuna.

IPCCren bosgarren ebaluazio-txostenean oinarrituz (AR5) [2], honako hauek dira hiri-eskualdeei eragin diezaieketen gertaerak: muturreko tenperatura-gertaerak; hotz- eta bero-boladak (bero-boladen ondoriozko baso-suteak barne); uholdeak, ekaitzak eta itsas mailaren igoera prezipitazio handien ondorioz; eta, klima-aldaketa bere osotasunean hartuz, tenperaturaren igoera eta ondoriozko klimaren aldaketa. Beraz, horiek izango dira azterketan identifikatuko diren mehatxuak.

Bilaketarako gako-hitzak zehazteko, IPCCk identifikatutako mehatxu nagusiak eta ikerketa-galderak hartu dira kontuan. Gako-hitzek, mehatxu bakoitzarentzat, «kalteberatasuna/arriskuaren ebaluazioa» eta «eremu historikoaren» sinonimoak konbinatzen zituzten, gako-hitz bakoitzaren erroa eta litezkeen aldaerak zehaztuz. Web of Science eta Scopus datu-baseen webgunean bilaketak egiteko, izenburua, gako-hitza eta laburpena aukera daitezke. Guztira 616 emaitza lortu ziren bi plataformetan gako-hitzen konbinazio guztiekin. Lehenengo filtroa izenburua izan zen, eta gaiarekin erlazionatutako artikuluak aukeratu ziren. Urrats hori bilaketa bakoitzean eta webgune bietan jarraitu zen, bikoiztutako artikuluak ezabatuz. Bigarren 
urratsean, artikulu guztien laburpenak irakurri ziren, arrisku-ebaluaziorako metodologiaren bat edo klima-aldaketarekin lotutako mehatxuren batek hirigune historikoan duen eragina aztertzen zuten egiaztatzeko. Baheketa horren ondoren, 34 artikulu posible gelditu ziren; azken artikulu horien testuanalisi osoa egin zen, eta batzuk baztertu egin ziren. Guztira, 29 artikulu identifikatu eta aztertu ziren (1. irudia). Hautaturiko artikuluak osorik berrikusi eta sailkatu ziren, landutako mehatxuaren eta lotutako arriskuen arabera (mehatxua, esposizioa, kalteberatasuna).

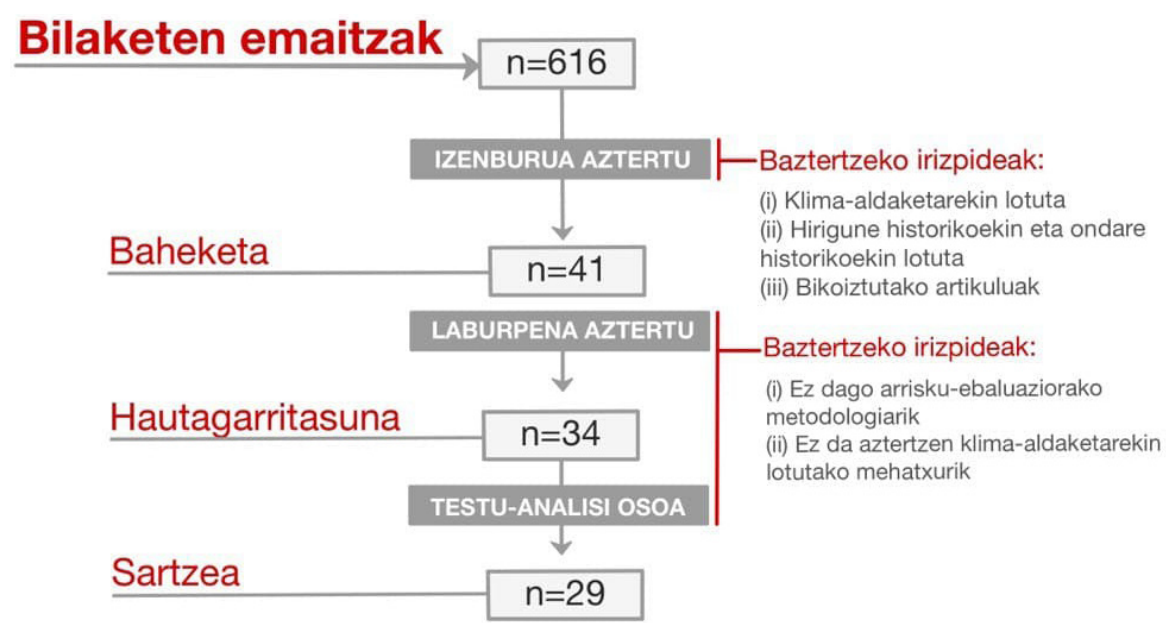

1. irudia. Literatura-bilaketa eta ebaluazioa, azterketa kritikoan egokiak diren artikuluan sartzeko ([12]-tik egokitua).

\subsection{Arriskuaren alderdiak eta dimentsioak aztertutako metodologietan}

Hogeita bederatzi artikuluen berrikuspena baliagarria izan zen arriskuaren alderdiak identifikatzeko (mehatxua, esposizioa, kalteberatasuna) eta horren dimentsio guztiak kontsideratzeko, hots, sozialak, ekonomikoak, kulturalak, gobernantzakoak (zerbitzuak eta baliabideak) eta fisikoak (azpiegitura, elementu eta eraikin guztien ezaugarri ukigarriak). Kontuan izan behar da arriskua azterketa-faseetan ebaluatzen dela, mehatxua karakterizatua izan behar dela esposizioaren analisia egiteko, eta biak, mehatxua eta esposizioa, ebaluatu behar direla sistema baten kalteberatasuna aztertzeko. Horregatik, emaitzak honela sailka daitezke: (i) mehatxu-probabilitatea eta larritasuna bakarrik ezaugarritzen dituzten metodologiak; (ii) esposizioa ere kontuan hartzen duten metodologiak; eta (iii) kalteberatasuna ebaluatzen jarraitzen duten metodologiak, sentikortasunaren eta ondorioei aurre egiteko ahalmenaren artean bereizten dutenak [2]. 
Laura Quesada-Ganuza, Leire Garmendia, Irantzu Álvarez, Estibaliz Briz, Ane Villaverde

2. irudian ikus daitekeen bezala, mehatxuaren probabilitatea eta larritasuna hogeita bederatzi metodologietako zazpitan baino ez ziren aztertu, eta elementuen esposizioa bakarrean ebaluatu zen.

Kalteberatasuna hogeita bat artikulutan aipatzen zen, eta aztertu egin ziren, ikusteko sentsibilitate-adierazleak eta/edo ondorioei aurre egiteko ahalmen-adierazleak ere aipatzen zituzten. Sentsibilitatea artikuluen ia erdietan kontsideratzen zen, nahiz eta ikerketa gutxi batzuetan baino ez zen halakotzat hartzen, eta besteetan kalteberatasun izendatzen zen. Aurretik aipatutako kategoriak kontuan hartuta, eta kalteberatasun-alderdiei dagokienez, hemeretzi artikulutan sentsibilitate fisikoa aztertzen zen, eta horietatik zortzik bakarrik hartzen zituzten kontuan beste alderdi batzuk. Kalteberatasun fisikoa ardatz zuten metodologien artean, eraikinek uholdeekiko duten kalteberatasuna zortzitan hartu zen kontuan, eta aktiboek oro har klima-aldaketarekiko duten kalteberatasun fisikoa lautan. Gainerako bi metodologiek kalteberatasun fisikoa kontuan hartu gabe baloratzen zuten kalteberatasuna, eta gobernatzearen kalteberatasun eta egokitzapen-gaitasunean [14] eta egokitzapen sozialaren gaitasunean jartzen zuten arreta [15]. Metodologia batzuetan, kontuan hartzen zen kalteberatasun sozioekonomikoa ere, biztanleek mehatxuari aurre egiteko duten gaitasuna aztertuz. Balio kulturala Gandini et al.-ek bakarrik aztertu zuten hainbat ikerlanetan $[16,17,18]$, eta artikulu bakar batean [19] lantzen ziren uholdeei buruzko guztiak.

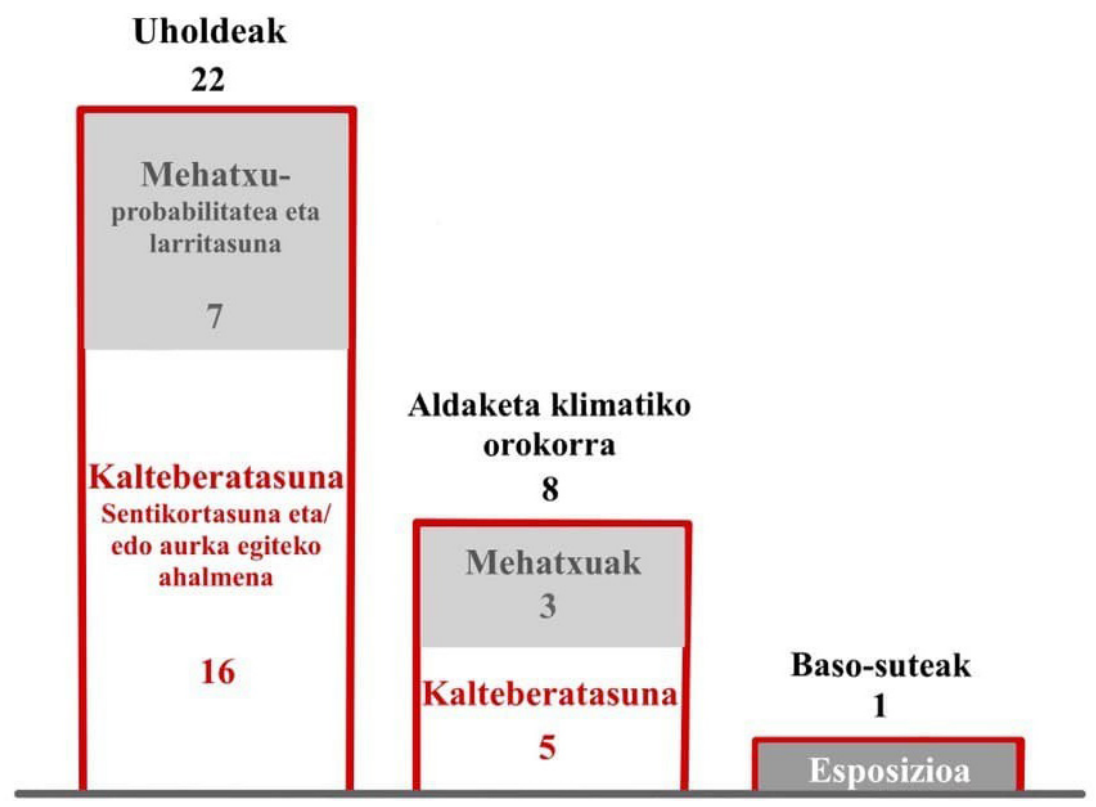

2. irudia. Azterketaren emaitzen laburpena. 


\subsection{Mehatxuak}

3. irudiak mehatxuen araberako berrikuspen kritikoaren emaitzak aurkezten ditu. Literaturan, prezipitazioen edo itsas mailaren igoeraren ondorioz gertatzen diren uholdeak dira gehien aztertzen den mehatxua (hogeita bederatzi artikuluetatik hogeita bitan). Uholdeak, beste mehatxuekin batera, mehatxu anitzeko hiru artikulutan hartzen ziren kontuan [20, 21, 22], eta gainerako hemeretzi metodologietan uholdeak bakarrik aztertzen ziren. Klima-aldaketak eragindako klima-aldaketa orokorra beste zortzi artikulutan kontsideratzen zen mehatxu. Baso-suteak artikulu bakar batean hartzen ziren mehatxutzat [23]. Hotz- eta bero-boladak, aldiz, ez ziren mehatxutzat hartu arrisku anitzeko artikulu batean ere.

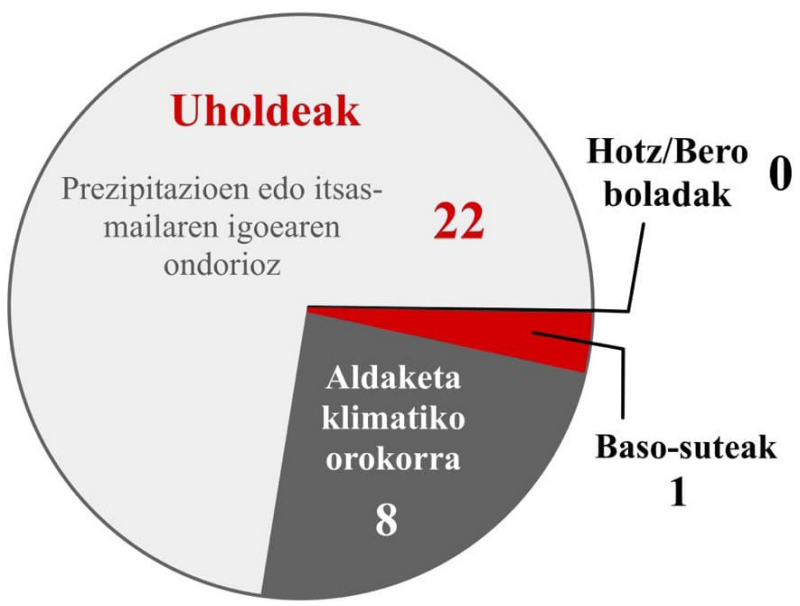

3. irudia. Arriskua aztertzen duten artikuluak, mehatxuen arabera sailkatuta.

\subsection{Azterketa kritikoaren emaitzak}

Klima-aldaketarekin lotutako mehatxuetatik eta muturretako gertakizunetatik abiatuz, ondorioak argiak izan ziren: bibliografiaren zati handi batek itsas mailaren igoerak edo ekaitzek eragindako uholdeak bakarrik aztertzen zituen, eta azterlan askok baldintza klimatikoen aldaketa orokorrari buruzko ikerketak egin zituzten. Aldiz, hotz- eta bero-boladak ez ziren aipatzen aztertutako artikuluetan.

Sarreran azaldu den bezala, bibliografian, askotan, hiriguneen kalteberatasuna haien baldintza sozioekonomiko eta fisikoekin lotzen da, hala nola kokapen geografikoarekin, materialarekin, hiri-bilbearekin eta -morfologiarekin, aberastasunarekin, gobernantza-sistemarekin, etab. [24]. Ezaugarri horiek baldintzatuko dute inpaktuen gogortasuna, klima-aldaketa eta 
Laura Quesada-Ganuza, Leire Garmendia, Irantzu Álvarez, Estibaliz Briz, Ane Villaverde

horrekin lotutako muturreko gertaerak kontuan hartzen direnean. Hirigune historikoen kasuan, azterketak agerian utzi zuen kontzentrazio handia zegoela eraikitako ingurunearen kalteberatasun fisikoan, eta sistemaren beste alderdi batzuen ahultasunak ez zirela kontuan hartu. Beste toki batzuetan dokumentatu dira klima-aldaketaren ondorioak aniztasun kulturalean eta elkarrekintza soziokulturalean, komunitate-sentimenduaren galeraren, ezagutza tradizionalaren, identitate kulturalaren eta sistema natural eta sozioekonomikoen gaineko inpaktuak [2, 6, 25], baina azterlan gutxik hartu dituzte aintzat klima-inpaktuak kultura-ondarean, ikuspegi holistiko baten bidez [26].

Gaur egungo iragarpenen arabera, mende honen amaieran iraupen eta intentsitate handiagoko bero-boladak egongo dira, gutxienez urtean behin [27]. Bero-boladetan izaten diren tenperatura altuak, sarritan, areagotu egiten dira hirietako bero-uhartearen efektuaren ondorioz (UHI, Urban Heat Island) [28], eta hiriguneetan inguruetako landa-eremuetan baino tenperatu altuagoak izaten dira. Bero-boladen efektuen artean, aipatzekoak dira giza osasunean eta hilkortasunean dituzten ondorioak, ingurumen-inpaktuak eta inpaktu ekonomikoak [29]. Inpaktu horiek nabarmenagoak dira populazio-dentsitate handiko hiriguneetan, hala nola hirigune historikoetan; beraz, halakoak oso kalteberak izango dira muturreko tenperatura altuko gertakarietan. Hori guztia dela eta, funtsezkoa da gertaera hau ikertzea, eta, azterketa honetan ikusi denez, bero-boladak kontuan hartzen dituzten arriskuak ebaluatzeko metodologiak behar dira eremu historikoetarako.

\section{FUNTSEZKO ADIERAZLEETARAKO AURRETIAZKO PROPOSAMENA}

Frogatu den bezala, arriskuen ebaluaziorako metodologiak holistikoak izan behar dira, eremu historikoak bero-boladen aurrean babesteko. Testuinguru holistikoetan, dimentsio fisikoekin batera, kontuan hartu behar dira gizarte-, ekonomia-, kultura-eta gobernantza-dimentsioak ere, eta parametro edo adierazle espezifikoak zehaztu behar dira bakoitzaren arriskua ebaluatzeko. Adierazle indibidualak eta konposatuak kalteberatasunaren eta arrisku-ebaluazioaren oinarriak dira, eta tresna arruntenen artean daude. Neurgarriak ez diren baldintzei buruzko informazioa sortzeko eta modu ezberdinean neurtutako datuak alderatzeko erabiltzen dira, neurketa konplexuak zenbaki bakar batean sintetizatuz [30].

Kalteberatasuna eta arriskua ebaluatzeko, hainbat ikuspegi eta metodologia daude. Egokiena aukeratzeko, helburua, ebaluatuko den sistema, denbora eta baliabideak hartu beharko dira kontuan. Ebaluazioaren hasieran, hainbat alderdi zehaztu beharko dira: helburuak (zergatik), aztertzen den sistema (nor/zer; kasu honetan, hirigune historikoa), estres-faktoreak 
(zertarako; guretzat, bero-bolada) eta denbora-tartea (noiz) [10, 11]. Bibliografian bi ebaluazio mota bereizi dira, analisi-eskalaren arabera: goitik beherako eta behetik gorako ebaluazioak [11]. Bereizketa hori kalteberatasunaren kontzeptualizazioari dago lotuta, emaitza edo helmuga gisa edo testuinguru edo abiapuntu gisa hartzen den, eta konbinatu egin daitezke.

Nahiz eta bero-boladak modu desberdinean definitzen diren eskualdeko klimaren arabera, WMOk bero-larrialdiei buruz dituen orientazioak (WMONo.1142) honela definitzen ditu bero-boladak: ezohiko bero lehorrak edo bero hezeak, gutxienez bizpahiru egun iraun dezaketenak eta giza jardueretan eragin nabarmena izan dezaketenak [31]. Bero-boladak karakterizatzeko adierazle nagusiak, beraz, tenperatura eta hezetasun erlatiboa dira, horrek definituko baitu bero-bolada lehorra edo hezea den [32]. Ondorioz, esposizioaren eta kalteberatasunaren adierazleek bero handiaren, hezetasun erlatibo baxu edo altuaren eta hirigune historiko baten sistema osatzen duten elementuen arteko kausa-efektuko erlaziotik eratorri behar dira, esposizio-aldagai gehigarriak barne.

UHIren ondorioei buruzko azterlanek erakusten dute bere intentsitatean eragina duten faktore nagusiak hiriguneetako banaketa morfologikoa - eragina baitu itzaletan eta aireztapenean -, hiri-elementuen ezaugarri teknikoak, eta mota eta eremu berdeen banaketa direla [33]. Hirien geometriak eta materialek eragina duten haizearen fluxuan, energia-xurgapenean eta gainazaleko islapen-propietateetan - uhin-erradiazio luzea atmosferara itzultzen dute- [28], eta horrek, aldi berean, UHI efektua baldintzatzen du.

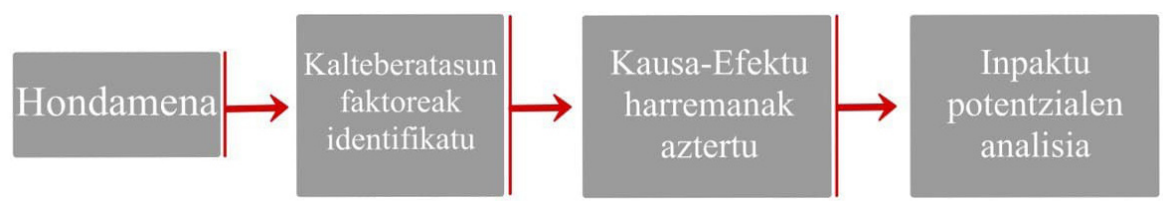

4. irudia. Adierazleen garapena ([34]-tik egokitua).

Hirigune historikoak osatzen dituzten elementuak definitzeko, bi ikuspegitatik heldu behar zaio sistemari: hiri-sistema gisa eta multzo historiko gisa. Adierazleak funtsezko dokumentuak berrikusiz bildu dira, hiri-ikuspegitik, herritarren ongizatearen ikuspegitik eta material historikoen higaduraren ikuspegitik. Adierazleak identifikatzeko, 4. irudiko eskemari jarraitu diogu. Hirigune historikoa hiri-sistema baten [35] eta hiri-paisaia historikoetan esanahi-eramaileak gehitzearen [36] arteko konbinaziotzat hartzen da, eramaile bakoitza hiri-sistema osagaiarekin parekatuz. Ikuspegi holistikoa emateko, sistemaren dimentsio bakoitza ebaluatu behar da, bibliografiaren berrikuspenean ikusi den bezala, alderdi sozialak eta ekonomikoak, kulturalak, gobernantzakoak eta fisikoak bereiziz. 
Laura Quesada-Ganuza, Leire Garmendia, Irantzu Álvarez, Estibaliz Briz, Ane Villaverde

\section{Hiri-sistema}

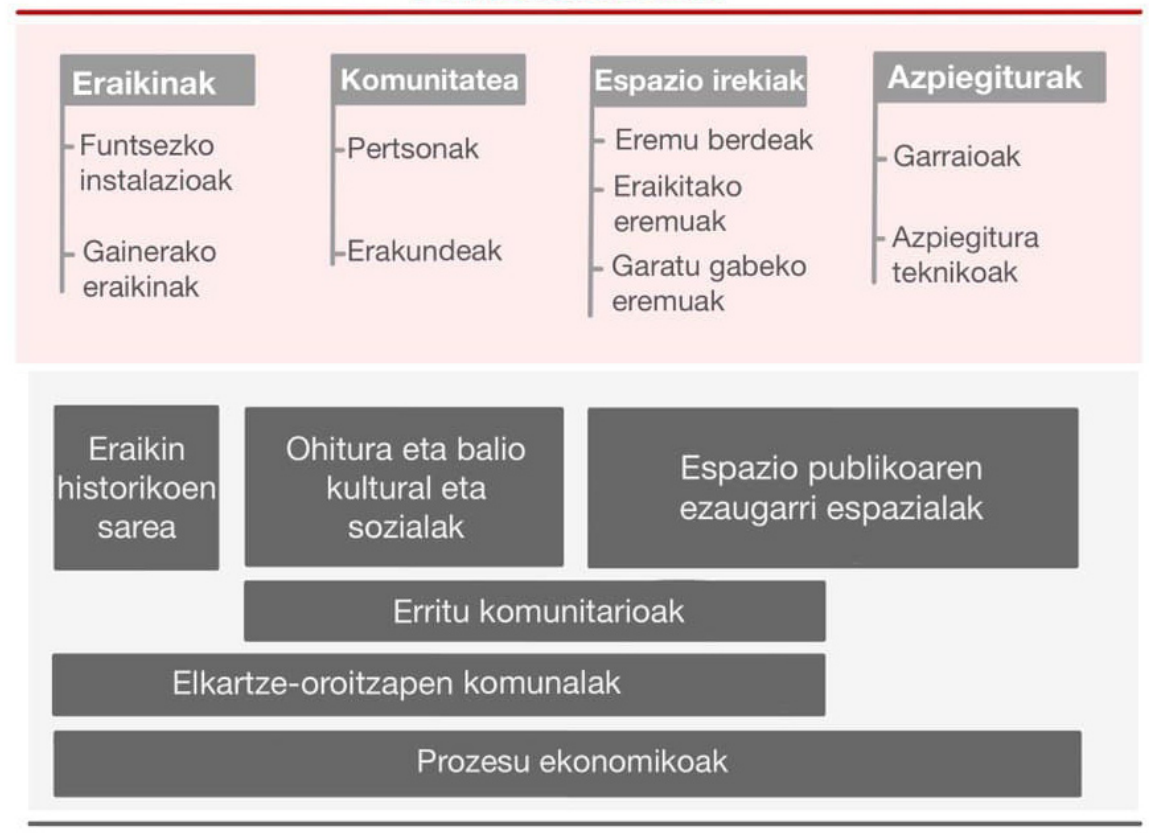

\section{Hiri historikoaren sarea}

5. irudia. Hirigune historikoen analisia adierazleen garapenerako ([12, 13]-an oinarrituz).

Adierazleak, beraz, bero-boladen eta eremu historikoaren elementuetan eta haien alderdi desberdinetan ezaugarritu diren bero-boladek eta UHIk izan ditzaketen inpaktuen emaitza dira. Adierazleak hurbilketa honen bidez garatu ahal izango dira IPCCren AR5 esparruarekin konbinatuz. Beraz, proposatutako adierazleek ordena horri jarraitzen diote: mehatxuaren karakterizazioa, esposizioa eta kalteberatasuna, sentikortasunaren eta aurre egiteko gaitasunaren artean banatuta. 5. irudiak adierazleen analisirako erabilitako prozedura laburbiltzen du.

Mehatxuen adierazleei dagokienez, aipaturiko bero-boladen karakterizazioa honako faktore nagusi hauetan oinarritzen da: tenperatura, hezetasuna, eguzkiarekiko esposizioa eta haizea. Hezetasun-aldaketek material tradizionaletan izan ditzaketen eragin ezberdinak direla eta, adierazle gehigarri modura hezetasun-zikloak eta kolpeak identifikatu dira [37].

Esposizioa hiri-eremuen oinarrizko bi elementu fisikotan banatzen da: eraikinak eta espazio irekiak. Eraikin baten esposizioa eguzkiaren argiarekiko esposizioaren arabera definitzen da, fatxadaren eguzki-erradiazioaren esposi- 
zio-denboraren arabera kalkulatuz, eraikinaren orientazioaren arabera, eta fatxadaren esposizio-angeluak eta inguruko eraikinetatik sor daitezkeen itzalak kontuan hartuz. Bestalde, espazio irekiek UHI adierazleak gehitzea eskatzen dute, hala nola Sky View faktorea, zeinak beroa biltegiratzeko gaitasuna duen hiri-espazio baten proportzioa zehazten duen [38] eta Urban Canyon efektuan eragina izan dezakeen [28]. Espazio irekietarako beste adierazle garrantzitsu bat elementu berdeen presentziarekin dago lotuta, eta Normalized Difference Vegetation Index (NDVI) deituriko indizearen bidez egin daiteke, zeina landaretzaren kuantifikazioan oinarritzen den, sateliteko irudien analisiaren bidez. Beroarekin erlazionatzen diren beste hiri-ezaugarri batzuk ozono troposferikoaren $\left(\mathrm{O}_{3}\right)$ maila eta kutsadura akustikoa dira. Ikerketa ugari dago frogatzen dutenak ozono-mailak areagotu egin daitezkeela baldintza meteorologiko zehatzetan, hala nola tenperatura altuetan, eguzki-erradiazio bortitzetan eta eguzki-ordu luzeetan; bero-boladen ezaugarri dira horiek guztiak [39], eta ondorioak izan ditzakete hirietako populazioaren osasunean [40]. Kutsadura akustikoari dagokionez, ikerketek erakutsi dute zarata-maila handia duten eremuetan bizi direnek euren etxea gutxiago aireztatzeko joera dutela, eta horrek bero-biltegiratzea areagotzen du eraikinaren barruan [41].

Sentsibilitate-adierazleek hiru osagai dituzte: gizarte-sentsibilitatea, eraikinak eta espazio irekiak. Azken biek dimentsio fisikoa, ekonomikoa eta kulturala hartzen dituzte kontuan. Gizarte-sentsibilitatea biztanleriaren ezaugarrien araberakoa da, bai adin-taldeen eta datu sozioekonomikoen arabera, eta bai biztanleria-dentsitatearen arabera ere. Eraikinen sentsibilitate-adierazleak hiru dimentsio nagusitan banatzen dira: fisikoa, ekonomikoa eta kulturala. Sentsibilitate fisikoa bero-boladen baldintzetan material tradizional sentikorren higaduran oinarritzen da batez ere [37], baita materialen ezaugarri termikoetan ere, hala nola haien albedo eta difusio termikoaren tasetan. Alderdi ekonomikoak eraikin baten erabileran oinarritzen dira, ekoizpenerako edo etxebizitza gisa edota bere balio turistikoagatik. Kultura-sentsibilitatearen adierazle nagusiak oroimen kolektiboen, erritualen edo tradizioen sinbolismoa dira. Espazio publikoetako eraikinen sentsibilitateari dagokionez, adierazleak lehen aipatu ditugun hiru kategoria nagusietan banatzen dira, baita materialen eguzki-islapena ere, bere sentsibilitate fisikoaren arabera.

Sentsibilitate-adierazleen kasuan bezala, ondorioei aurre egiteko gaitasunaren dimentsioak sozialak eta fisikoak dira, eraikinak eta espazio irekiak kontuan hartuta. Gizartearen aurre egiteko gaitasuna aztertzean, bi adierazle nagusiak hauek dira: osasun-zerbitzuaren eskuragarritasuna (ospitalerako distantzia eta ospitaleko oheen eskuragarritasuna) eta herritarren mehatxuarekiko kontzientzia, hala nola larrialdi-planen existentzia. Eraikinen eta espazio irekien kasuan, bi elementuak antzeko ezaugarrietan oinarritzen dira: irisgarritasuna eta igogailuak, eta anbulatorioetarako eta suhiltzaileentzako irisgarritasuna, hurrenez hurren. 
Laura Quesada-Ganuza, Leire Garmendia, Irantzu Álvarez, Estibaliz Briz, Ane Villaverde

\section{ONDORIOAK}

Lan honetan, arriskua ebaluatzeko adierazle batzuk proposatu dira lehen zatian identifikatu diren ezagutza-hutsuneei heltzeko, hau da, hirigune historikoetan bero-boladen mehatxuaren ebaluaziorako metodologien urritasunari. Geruza historikoa duen hiri-sistema edo eremuaren analisia malgua da eta beste edozein eremutara molda daiteke. Datuen eskuragarritasuna kontuan hartuta garatu dira, errepikagarritasuna eta emaitzen konparazio erraza bermatuz.

Azterketa honen etorkizuneko helburu bat hiri-eremu historikoetarako arriskuak ebaluatzeko metodologia oso bat sortzea izango da, geografia-informaziorako sistemetan (GIS) oinarritua, eskuragarria eta errepikatzeko erraza.

\section{ESKER ONAK}

Autoreek Europako Batzordearen finantzaketa eskertu nahi dute, SHELTER proiektuaren bidez (GA 821282), baita Eusko Jaurlaritzako IT1314-19 eta UPV/EHUko GIU19/029 ikerketa-taldeek emandako laguntza ere. Azkenik, egileek SAREN ikerketa-taldearen bidez jasotako laguntza ere eskertu nahi dute.

\section{BIBLIOGRAFIA}

[1] WMO. 2013. WMO Statement on the Status of the Global Climate in 2012. http://www.wmo.int/pages/mediacentre/press_releases/documents/ WMO_1108_EN_web_000.pdf

[2] IPCC. 2014. Climate Change 2014: Synthesis Report. Contribution of Working Groups I, II and III to the Fifth Assessment Report of the Intergovernmental Panel on Climate Change [Core Writing Team, R.K. Pachauri and L.A. Meyer (eds.)]. IPCC, Geneva, Switzerland, $151 \mathrm{pp}$.

[3] UN-Habitat. 2016. World Cities Report 2016: Urbanization and Development - Emerging Futures. https://unhabitat.org/world-cities-report

[4] EEA. 2017. Climate Change, Impacts and Vulnerability in Europe. 2016: An Indicator-Based Report. https://doi.org/10.2800/534806

[5] Sabbioni, C., Brimblecombe, P., Cassar, M., eta Noah's Ark. 2010 (Project). «The atlas of climate change impact on European cultural heritage: scientific analysis and management strategies». EC cultural heritage research series , 19, London.

[6] Cassar, M., Young, C., Weighell, T., Iccrom, Icomos, Sheppard, D., Bomhard, B., Rosabal, P., eta UNESCO. 2007. «Climate Change and 
World Heritage». Report on Predicting and Managing the Impacts of Climate Change on World Heritage and Strategy to Assist States Parties to Implement Appropriate Management Responses. Edited by Augustin Colette.

[7] Markham, A., Brabec, E., Burke, S., Cox, P., Daly, C., Diop, A., DowNES, J. et al. 2019 (Project) The Future of Our Pasts: Engaging Cultural Heritage in Climate Action - Outline of Climate Change and Cultural Heritage.

[8] Bonazza, A., Maxwell, I., DrdáckÝ, M., Vintzileou, E., eta Hanus, C. SAfeguarding. 2018. «Cultural Heritage from Natural and Man-Made Disasters: A Comparative Analysis of Risk Management in the EU». Luxembourg: Publications Office of the European Union.

[9] Council of Europe. 2018. «Recommendation CM/Rec (2018)3 of the Committee of Ministers to Member States on Cultural Heritage Facing Climate Change: Increasing Resilience and Promoting Adaptation ».

[10] UNDRO. 1980. «Natural Disasters and Vulnerability Analysis : Report of Expert Group Meeting, 9-12 July 1979». Geneva: Office of the United Nations Disaster Relief Coordinator.

[11] Berrang-Ford, L., Pearce, T., eta Ford, J. D. 2015. «Systematic Review Approaches for Climate Change Adaptation Research». Regional Environmental Change 15, 5, 755-69. https://doi.org/10.1007/s10113-014-0708-7

[12] Xiao, Y., eta Watson, M. 2017. «Guidance on Conducting a Systematic Literature Review». Journal of Planning Education and Research, 39, 1: 93112. https://doi.org/10.1177/0739456X17723971

[13] Grant, M. J., eta Boоth, A. 2009. «A Typology of Reviews: An Analysis of 14 Review Types and Associated Methodologies». Health Information and Libraries Journal, 26, no. 2: 91-108. https://doi.org/10.1111/j.1471-1842.2009.00848.x

[14] Sesana, E., Gagnon, A. S., Bertolin, C., eta Hughes, J. 2018. «Adapting Cultural Heritage to Climate Change Risks: Perspectives of Cultural Heritage Experts in Europe». Geosciences (Switzerland) 8, no. 8: 1-23. https:// doi.org/10.3390/geosciences8080305

[15] Bernardini, G., Postacchini, M., Quagliarini, E., D’orazio, M., eta BrocchinI, M. 2019. «Flooding Pedestrians' Evacuation in Historical Urban Scenario: A Tool for Risk Assessment Including Human Behaviors». RILEM Bookseries 18: 1152-61. https://doi.org/10.1007/978-3-319-994413_124

[16] Gandini, A., Garmendia, L., Prieto, I., Álvarez, I., eta San-José, J.-T. 2020. «A Holistic and Multi-Stakeholder Methodology for Vulnerability Assessment of Cities to Flooding and Extreme Precipitation Events». Sustainable Cities and Society 63. https://doi.org/10.1016/j.scs.2020.102437

[17] Gandini, A., Prieto, I., Garmendia, L., San-José, J.-T., eta Egusquiza, A. 2018. «Adaptation to Flooding Events through Vulnerability Mapping in Historic Urban Areas». The International Archives of the Photogrammetry, Remote Sensing and Spatial Information Sciences - ISPRS Archives, 42:221-26. https://doi.org/10.5194/isprs-archives-XLII-3-W4-221-2018 
Laura Quesada-Ganuza, Leire Garmendia, Irantzu Álvarez, Estibaliz Briz, Ane Villaverde

[18] Gandini, A., Garmendia, L., eta San Mateos, R. 2017. «Towards Sustainable Historic Cities: Adaptation to Climate Change Risks». Entrepreneurship and Sustainability Issues 4, no. 3: 319-27. https://doi.org/10.9770/ jesi.2017.4.3S(7)

[19] Vojinovic, Z., Hammond, M., Golub, D., Hirunsalee, S., Weesakul, S., Vorawit Meesuk, Medina, N., Sanchez, A., Kumara, S., eta Abbott, M. 2016. «Holistic Approach to Flood Risk Assessment in Areas with Cultural Heritage: A Practical Application in Ayutthaya, Thailand». Natural Hazards 81, no. 1: 589-616. https://doi.org/10.1007/s11069-015-2098-7

[20] Forino, G., Mackee, J., eta Von Meding, J. 2016. «A Proposed Assessment Index for Climate Change-Related Risk for Cultural Heritage Protection in Newcastle (Australia)». International Journal of Disaster Risk Reduction 19: 235-48. https://doi.org/10.1016/j.ijdrr.2016.09.003

[21] Kotova, L., Jacob, D., Leissner, J., Mathis, M., eta Mikolajewicz, U. 2019. «Climate Information for the Preservation of Cultural Heritage: Needs and Challenges». Communications in Computer and Information Science 961: 353-59. https://doi.org/10.1007/978-3-030-12957-6_25

[22] Ravankhah, M., Chmutina, K., Schmidt, M., eta Bosher, L. 2017. «Integration of Cultural Heritage into Disaster Risk Management: Challenges and Opportunities for Increased Disaster Resilience». Going Beyond. Heritage Studies 2, edited by M.-T. Albert et al. (eds.), 307-21. Springer International Publishing AG. https://doi.org/10.1007/978-3-319-57165-2

[23] Mallinis, G., Mitsopoulos, I., Beltran, E., eta Goldammer, J. G. 2016. «Assessing Wildfire Risk in Cultural Heritage Properties Using High Spatial and Temporal Resolution Satellite Imagery and Spatially Explicit Fire Simulations: The Case of Holy Mount Athos, Greece». FORESTS 7, no. 2. https://doi.org/10.3390/f7020046

[24] Georgi, B., Swart, R., Marinova, N., Hove, B., Jacobs, C., KlosterMANN, J., et al. 2012. «Urban Adaptation to Climate Change in Europe Challenges and Opportunities for Cities Together with Supportive National and European Policies», Rep. No. 2/2012. https://doi.org/10.2800/41895

[25] Adger, W. N., Barnett, J., Brown, K., Marshall, N., eta O’Brien, K. 2013. «Cultural Dimensions of Climate Change Impacts and Adaptation». Nature Climate Change 3, no. 2: 112-17. https://doi.org/10.1038/ nclimate 1666

[26] Gandini, A., Egusquiza, A., Garmendia, L., eta San-Jose, J.-T. 2018. «Vulnerability Assessment of Cultural Heritage Sites towards Flooding Events». Florence Heri-Tech - The Future Of Heritage Science And Technologies, Vol. 364. IOP Conference Series-Materials Science and Engineering. Dirac House, Temple Back, Bristol Bs1 6be, England: Iop Publishing Ltd. https://doi.org/10.1088/1757-899X/364/1/012028

[27] Lemonsu, A., Viguié V., Daniel M., eta Masson V. 2015. «Vulnerability to Heat Waves: Impact of Urban Expansion Scenarios on Urban Heat Island 
and Heat Stress in Paris (France)». Urban Climate 14: 586-605. https://doi. org/10.1016/j.uclim.2015.10.007

[28] Gartland, L. 2010. «Heat islands: understanding and mitigating heat in urban areas». London SE - xiii, 192 p.: il.: Earthscan.

[29] Zuo, J., Pullen S., Palmer, J., Bennetts, H., Chileshe, N., eta Ma, T. 2015. «Impacts of Heat Waves and Corresponding Measures: A Review». Journal of Cleaner Production 92: 1-12. https://doi.org/10.1016/j. jclepro.2014.12.078

[30] Kalisch, A., Y Satapath S., Porsché I., R Rolke D., Bhatt S., Tomar S., eta NAIR S. 2014. «A Framework for Climate Change Vulnerability Assessments». CCARDESA.

[31] World Meteorological Organization. 2018. Guidelines on the Defintion and Monitoring of Extreme Weather and Climate Events. https://doi. org/10.1109/CSCI.2015.171

[32] Chen, X., Li, N., Liu J., Zhang, Z., eta Liu, Y. 2019. «Global Heat Wave Hazard Considering Humidity Effects during the 21st Century». International Journal of Environmental Research and Public Health 16, no. 9. https:// doi.org/10.3390/ijerph16091513

[33] Li, D., eta Bou-ZEID, E. 2013. «Synergistic Interactions between Urban Heat Islands and Heat Waves: The Impact in Cities Is Larger than the Sum of Its Parts». Journal of Applied Meteorology and Climatology 52, no. 9: 2051-64. https://doi.org/10.1175/JAMC-D-13-02.1

[34] UNESCO. 2010. Managing Disaster Risks for World Heritage. Paris: UNESCO World Heritage Center. https://whc.unesco.org/en/managingdisaster-risks/

[35] Rus, K., Kilar, V., eta Koren, D. 2018. «Resilience Assessment of Complex Urban Systems to Natural Disasters: A New Literature Review». International Journal of Disaster Risk Reduction 31, no. March: 311-30. https:// doi.org/10.1016/j.ijdrr.2018.05.015

[36] Araoz, G. F. 2008. «World-Heritage and Defining Historic Protecting Urban Landscapes: Authenticity». APT Bulletin: Journal of Preservation Technology 2-3, no. 39: 33-37.

[37] Brimblecombe, P., Grossi C. M., eta Harris I. 2011. «Climate Change Critical to Cultural Heritage». Survival and Sustainability, 195-205. https://doi. org/10.1007/978-3-540-95991-5

[38] Dirksen, M., Ronda, R. J., Theeuwes, N. E., eta Pagani, G. A. 2019. «Sky View Factor Calculations and Its Application in Urban Heat Island Studies». Urban Climate 30: 100498. https://doi.org/10.1016/j.uclim.2019.100498

[39] Pyrgou, A., Hadjinicolaou, P., eta Santamouris, M. 2018. «Enhanced Near-Surface Ozone under Heatwave Conditions in a Mediterranean Island». Scientific Reports 8, no. 1: 9191. https://doi.org/10.1038/s41598-018$27590-\mathrm{z}$ 
Laura Quesada-Ganuza, Leire Garmendia, Irantzu Álvarez, Estibaliz Briz, Ane Villaverde

[40] Stedman, J. R. 2004. «The Predicted Number of Air Pollution Related Deaths in the UK during the August 2003 Heatwave». Atmospheric Environment 38, no. 8: 1087-90. https://doi.org/10.1016/j.atmosenv.2003.11.011

[41] NúÑez Peiró, M., Sánchez, C., Sanz-Fernández, A., Heredia, M., LóPezBueno, J., Neila, J., C. Linares, Díaz, J., eta Muñoz, G. 2020. «Exposure and Vulnerability towards Summer Energy Poverty in the City of Madrid: A Gender Perspective», In Press. 